\title{
Developing Technology-assisted Multi-disciplinary Learning Strategies
}

\author{
S. Gandhi ${ }^{a}$ S. Sankaran ${ }^{a}$ M. Er ${ }^{a}$ K. Orr ${ }^{a}$ and H. Khabbaz ${ }^{b}$ \\ ${ }^{a}$ Faculty of Design, Architecture and Built Environment, University of Technology Sydney, Australia \\ ${ }^{b}$ Faculty of Engineering and Information Technology, University of Technology Sydney, Australia \\ E-mail: shalinigandhi@student.uts.edu.au
}

\begin{abstract}
-
The construction industry is multi-disciplinary and collaborative in nature. Project managers are expected to understand the relations, roles and responsibilities in this collaborative working environment. Construction project managers need to be equipped with skills to process and understand the principles of interdisciplinary working. In order to keep pace with industry requirements, it is necessary for universities to teach subjects in tertiary education courses that educate and motivate construction students towards interdisciplinary working. This paper is based on a research project aimed at understanding opportunities and challenges for introducing subjects that require students from different disciplines to work together on an integrated project. In order to teach interdisciplinary working principles to project management students, a new post-graduate subject, Integrated Project Delivery, was introduced in the Master of Project Management at the University of Technology Sydney (UTS) as part of a construction sub-major. The subject was designed and teaching materials prepared based on inputs from architecture, engineering and construction management academics. In the teaching of the subject, interdisciplinary student teams were formed based on educational background and professional experience. An (pedagogical) action research approach was adopted to study the challenges and benefits of new ways of learning in line with the UTS learning strategies being adopted by academics. The main finding of this research concluded that projectbased learning is very valuable to both students and industry alike as it promotes working on a live project enthusiastically and gaining industry experience in new ways of working adopted by industry. Working in multi-disciplinary teams requires students to respect the other team participants from different backgrounds, inculcating values of team spirit and discouraging adversarial behaviours. Furthermore this research provides insights about student expectations from a postgraduate subject and their experience of a multi-
\end{abstract}

disciplinary working environment. This paper discusses both the successes and the issues faced during the teaching of this subject and suggest future directions for research and effective approaches to implementing interdisciplinary working in an educational environment.

\section{Keywords -}

Project-based learning; Multi-disciplinary teams in education; Flipped and blended learning; Collaboration; Interactive learning spaces; action research.

\section{Introduction}

The introduction of advanced technologies in the last decade has stimulated evolutionary changes in the construction industry, with impacts on engineering, architecture, construction management and related construction professions. Emerging trends in demographics, economics and globalization have increased competition in current business models and thus collaboration has become mandatory for survival [1]. There is a necessity for more practical multidisciplinary collaboration amongst industry professionals to deliver advanced construction projects while meeting client demands. An interdisciplinary working environment and integrated approach towards project delivery is considered to optimize efficiency and deliver better outcomes. In current education models most students spend the majority of their time within their individual disciplines working on projects that do not assist in building interdisciplinary teamwork or interdisciplinary communication skills [2].

Rapid changes in the construction industry arising from the prompt adoption of the latest and most advanced technologies is making it necessary for professionals to regularly update their knowledge and skills throughout their career [2]. The implementation of effective interdisciplinary collaboration in day-to-day professional work environment of the Architecture, Engineering and Construction (AEC) industry has not kept pace with advances in technology. To keep pace 
with the introduction of technology and industry requirements, construction project managers should pay more attention to the human side of professionalism and develop skills to be more flexible and adaptable to inevitable changes in their career and roles. Various studies have revealed a lag in the adoption of emerging trends in construction education as compared to the rapid advancements occurring in AEC industry [3, 4]. In the US, Europe and Australia, AEC students continue to be educated in separate faculties/schools, with little or no integration or collaboration between the disciplines. Within the higher education setting, advanced multidisciplinary collaboration frequently encounters resistance as the traditional silos of architecture, engineering and construction prove difficult to bridge. As in industry, lack of cooperation between the professions also exists in academia, and questions often arise as to who should be responsible for, or take ownership of, cross-disciplinary subjects - especially when such subjects span across faculties. Furthermore, education in construction management is under immense pressure to evolve in step with the demands of a rapidly evolving industry and to develop skills, strategies and attitudes that will prepare graduates for their working lives and inculcate adequate professionalism.

This research paper looks at how the subject content, teaching methods, and interdisciplinary teams in a postgraduate subject can be aligned to promote students' understanding of collaborative working and to develop the graduate attributes demanded by current construction industry practices. The research also evaluates industry expectations from construction management graduates and analyses student expectations from a subject offering interdisciplinary collaboration and project-based learning.

\section{Background}

In the case of attempts to introduce interdisciplinary learning in education, Fruchter [5] documents a collaboration between six universities across Europe, Japan, and the United States. An experimental framework was implemented, along with a tool kit to assist the interdisciplinary team members to collaborate successfully and to evaluate the outcomes. There are also several other instances of universities who have implemented and reported on individual cross-faculty collaborative design courses, such as the University of Sydney [6], Carnegie Mellon University [7], and Georgia Institute of Technology [8]. Other Universities in Australia, such as the University of South Australia and the University of Newcastle, have started to develop multi-disciplinary AEC courses at undergraduate level, but none appear yet to have attempted fully multi- disciplinary AEC courses at the postgraduate Masters level, despite institutions in the US, Europe and the UK having done so. The documented case studies often focus on the advances in information technology and its adoption amongst students, rather than how these strategies enhance educational practices in construction management.

The implementation of 'blended' learning procedures is comparatively recent in Australian education models. Blended learning combines face-toface learning with distance (out of class) learning with a goal of harnessing the positive characteristics of both teaching methodologies[9]. Constructivist theorists believe consequential learning can be accomplished through the implementation of realistic, simulated problems to be solved [10]. On the other hand, variation theorists emphasize the importance of students' experience of variation to address critical aspects of the subject matter [11]. Oliver and Trigwell [12] support the idea of combining blended learning with interdisciplinary team work to solve a complex problem, arguing that this allows students to experience the patterns of variation necessary to engender different perspectives and different ways of seeing things. Despite the various benefits of these education methods, there is still a lack of studies around interdisciplinary education in post-graduate courses which employ project-based learning in a 'flipped' and 'blended' learning environment, such as is being encouraged and trialled at universities like UTS.

The new postgraduate subject, Integrated Project Delivery, introduced into the UTS Master of Project Management degree attempts to fill a crucial gap in the education of construction management students. It combines a flipped and blended learning format with the advantages of new digitally advanced learning and teaching spaces that support and enhance students' learning experience. Extensive consultation with representatives of the relevant professional bodies and AEC industry was undertaken to ensure that the new subject meets current industry demands, equipping students with the attributes required by industry and thus assisting to increase the employability of UTS graduates.

\section{Methodology}

This research has examined the needs of the construction industry and the development of educational strategies to deliver skilled graduates equipped with the requisite professional experience. It has been concerned with developing practical knowing for advancing the human dimension of professionalism among students.

Action research methods were identified as most 
suitable for this study; with the plan-act-observe-reflect cycle used to collect data through reflective journals maintained by the academics involved. Thus the research brings together action and reflection, theory and practice in the pursuit of practical solutions to meet industry demands and more generally the flourishing of individual persons and their educational and professional communities [13]. Figure 1 represents the action research cycle adopted for this research and its relation to various stages in this project.

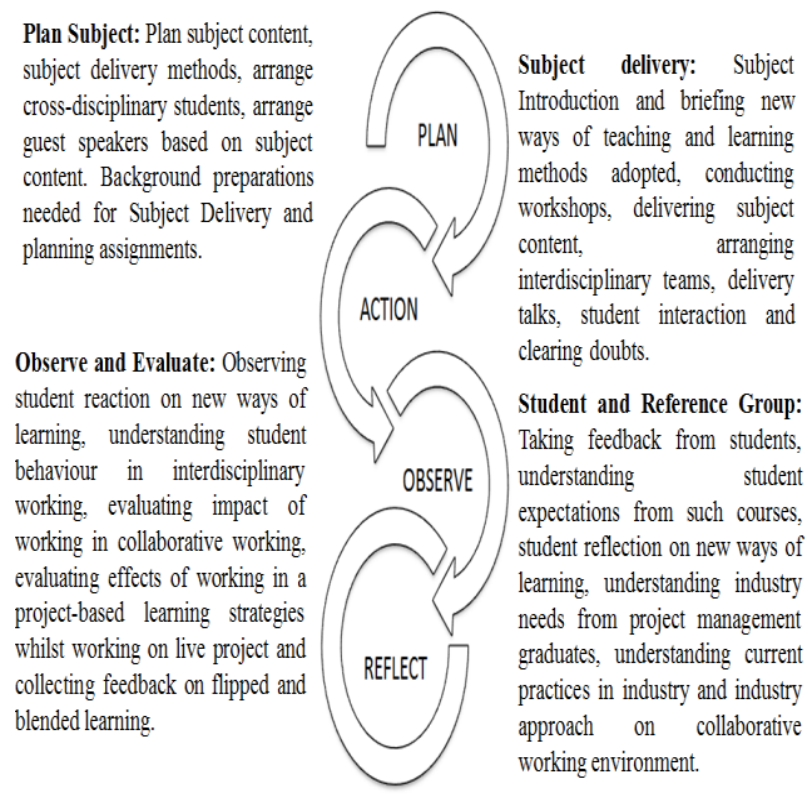

Figure 1: Project Action Research Cycle.

Stages included 1) Plan: Planning subject content matter and deliverables, methods of subject delivery; 2) Action: Subject delivery and workshops; 3) Observe and Evaluate: Observing effects of new ways of learning and collaboration during workshops and; 4) Reflect: Collecting student feedback and reflections from Industry Focus group interviews.

Further, four phases of this research can be described as: Phase I (Plan): This phase included conducting a literature review and referring it for purposes of subject delivery. This phase also included enrolling students from different disciplines into the subject. Phase II (Action): This phase dealt with subject delivery and conducting focus group interviews. About 26 students participated in this subject and a reference group of 12 participants was selected for focus group interviews. Phase III (Observe): Data was collected throughout the semester at he workshops held foe the subject. Observation regarding student reaction and behaviour for new way of learning was recorded. Student reflections about how the subject was taught and feedback through the university's feedback system. Industry expectation from such a subject was gathered through a focus group for future direction. Data was analysed with help of Nvivo 10, and findings were recorded. Phase IV (Reflect): Based on findings, and discussion among staff ideas for future teaching were gathered. These ideas have been incorporated for further teaching of this subject.

The new postgraduate subject, Integrated Project Delivery, in the UTS Master of Project Management (MPM) degree, incorporates a project-based learning approach. Within this subject, the action research cycle includes the use of drawings developed for a building project to solve simulated problems based on real-life scenarios derived from industry. The subject was taught using a $2 \times 2$ block workshop mode over the course of a semester supported by online reading materials and online forums. The subject tried to combine both flipped and blended learning about interdisciplinary design and construction management and was designed to provide students with the experience, tools, and methods needed to improve their understanding of construction management processes.

Students participating in the MPM course belonged to variety of backgrounds such as engineering, architecture and construction management and formed multi-disciplinary teams, working together to generate designs, contractual documents and tenders, while experimenting with different work practices to take maximum advantage of project based learning. The students collaborated from remote locations via webbased approaches, while working on a live project. As such, they were encouraged to utilize technologically advanced methods of communication, correspondence and coordination that combined face-to-face interactions with the virtual. The subject also made use of the sophisticated future learning spaces at UTS, which are equipped with interactive white boards, pods and other facilities to assist students to collaborate during team meetings. Students used the software installed on the Pod computers and interactive white boards in the collaborative learning space [14] to manipulate and mark-up drawings and models. The flat tables and moveable whiteboard screen zones were ideal for facilitating group interaction. Students were asked to view online tutorials and lessons in their own time, and to come to the classes ready to work in groups and to be mentored by external guest tutors at regular intervals.

At the conclusion of the subject, a student feedback survey was conducted to gather data that could be analyzed to understand various factors that contributed to the learning experience in this subject. 
A reference group was formed comprising representatives from relevant industry bodies and professional associations and senior managers from industry. A needs analysis was carried out with the reference group to determine industry expectations of UTS graduates working on complex construction projects. Data collected from the reference group and during two teaching workshops during the semester was analyzed to gauge the success of the subject and to inform decisions regarding further subject development. Therefore data was collected from a wide range of sources, including focus group discussions with industry professionals; the use of the Self \& Peer Assessment Resource Kit (SPARK) in the student workshops with protocols for peer review in blended learning environments proposed by McKenzie, Pelliccione [15]; and student feedback surveys (SFS), which included additional questions relevant to the evaluation of the teaching and learning strategies adopted. Nvivo 10 was used for coding and analysis purposes. The analysis provided some surprising results, articulated in the following sections.

\subsection{Subject Delivery Process}

Since the subject was part of a Postgraduate course with several students working in industry, it was considered appropriate that the subject content be delivered in workshop mode separated by a break to encourage students to experience working as virtual teams. Two workshops were conducted for the delivering of subject content. Each workshop lasted for two days; one was conducted at the beginning of semester, with the second held towards the end of semester.

Workshop 1: The first workshop was utilized to introduce the subject and its new learning and teaching methods. Student teams were formed based on professional and educational background.

A site visit to a selected live project was arranged and students had an opportunity to interact with real project clients as well as members from the project's architectural team and project management consultants. This helped them to gain experience on a live project, discovering the site constraints, environmental conditions, and project requirements and applying these reflectively to a problem-driven assignment.

Additional to the site visit, lectures were delivered by academics and industry professionals to familiarize students with various topics including: collaborative working in interdisciplinary teams, current practices in project management, advanced information technology tools for project management and communication, latest trends in the construction industry in Australia, working with government authorities, collaboration practices on large-scale projects, tendering processes and contractual agreements.

Assignments: After the first workshop students were asked to propose design changes and prepare tender documents based on their new designs as part of an assignment submission. Students were encouraged to use web-based communication tools for remote meetings. A virtual space was also created in UTS Online, a web-based tool to provide online learning to students. This virtual space provided for the maintenance of records, submission of weekly updates on frequency of communication, project progress and correspondence schedules. Self-assessment and group evaluation were conducted at two points during the period intervening between the two workshops to enhance productivity and outputs. The first SPARKPlus evaluation was set before the first assignment, such that results from evaluation and assignments were announced nearly at the same time. This allowed students to reflect on their teamwork and its effect on assignments. This in turn helped them to analyze the requirements of collaborative working.

Workshop 2: The second workshop was arranged towards the end of semester. Day 1 of the second workshop allowed students to interact with the contractors who had submitted tenders. At this time academics and industry professionals provided students with experience in selecting contractors, based not only on their quotations but also on an understanding of their work background and experience in similar projects. Day 2 involved presentations by the students of their work and understanding of the subject.

Following the second workshop, students were given a final assignment consisting of writing a brief personal reflection on the subject matter and learning experience, subject deliverables, methods of subject delivery and recommendations for future.

\section{Findings and Discussions}

Findings from this research are presented by following the sequence of (educational) action research, as shown earlier in Figure 1.

Stage1: Abstract Conceptualization. A review of the literature suggests that it is necessary to integrate current interdisciplinary working practices adopted by industry into the educational curriculum to prepare students to be work ready. Achieving the right mix of students in a cross-disciplinary subject is a cumbersome task that requires careful coordination with student administration (enrolment) authorities. This became particularly difficult when students with negligible professional construction experience were enrolled in the subject resulting in unbalanced teams. Taking into consideration the context of the case study project (the construction project management of a car park and 
associated infrastructure) the issue of unbalanced teams posed a major issue and in one case led to the merger of two student teams.

The problem of unbalanced teams manifested itself in the assignment submission, which was based on construction tenders and contracts. Another concern highlighted at this time was the split workshop mode. Students who were used to doing a continuous block and had other subjects running between the workshops found it difficult to maintain interest and engagement in the subject. Contingency plans to negate these issues will need to be further developed.

Stage 2: Active Experimentation. Classroom workshops which included implementation of planned actions. Data was collected during the workshops to understand the students' reactions to various new concepts adopted by this subject. Figure 2 shows team responses to a few key points observed during the workshops.

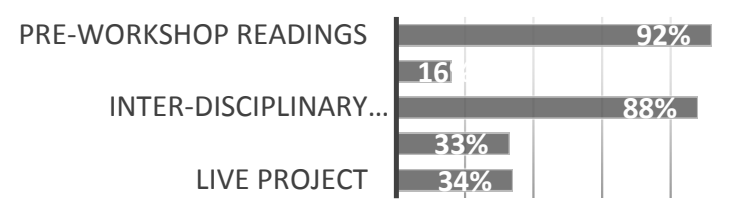

Figure 2: Data collection results from workshop. The percentage on bar chart represents students support.

As evident from the chart, the teams were not very comfortable with the small team size, which varied from 3-5 members from cross-disciplinary backgrounds. Most students suggested that a larger team size with two team members from each discipline would have assisted work distribution and more efficient outputs.

Nearly $90 \%$ of the teams favored working in collaboration with members from different backgrounds. They stated that such integration assisted in looking at the same problem from different perspectives.

Despite the experience gained from project-based learning, working on a live project was found to be stressful by a number of students. It demanded more accuracy from assignment submissions, which caused anxiety for those students who were not familiar with interpreting construction drawings.

Another significant finding was that students would have preferred the site visit to be scheduled outside of the time allocated to the first workshop. Students would have prefered the workshop hours to be entirely devoted to clarifying questions and building rapport with other team members. Pre-reading materials were found very useful by teams to understand interdisciplinary working strategies and current progress in AEC industry towards integration. However, students realized that in order to work efficiently for assignments, their teams had to be proactive and adopt some of the proper methods for smooth working in collaboration, as listed below:

1. Developing a detailed understanding of each team member's capabilities and documenting these.

2. Defining roles and responsibilities based on abilities and preparing a conflict resolution framework.

3. Establishing a communication framework including meeting schedules and correspondence routines.

4. Having a detailed discussion on the use of technologies for communication and preparing team agendas based on good project management principles.

5. Defining team protocols regarding document submissions.

6. Documenting all correspondence by individual team members as a means of to recording the team's progress on the project between workshops.

Stage 3: Concrete (Project) experience. Blend theory with practice. Following the workshops, focus group interviews were held with industry and academic experts. Their inputs on industry expectations from students were collected based on the following four general questions: 1) What is the current state of integrating works done by different teams in delivering projects in Australian AEC industry?; 2) What are some of the issues for integrating the work performed by different teams using current practices in industry, and how can these be addressed?; 3) What are the benefits of educating students about Integrated Project Delivery (IPD) practices to industry?; 4) What activities of collaborative working would you recommend be included in a subject that is designed to teach IPD? Feedback received from the industry focus group regarding the current state of integration is summarized in Table 1 .

Table 1. Industry Focus Group Feedback Resisting Integration

Lack of government policies.

Lack of contractual agreements.

Larger project teams.

Legality issues.

Tremendous governmental paperwork.

Lack of decision-making frameworks.

Differences in priorities and conflicts.

Traditional ways of working.

Lack of clarity on roles for large-scale projects.

Governance issues for complex processes. 
Perception of project deliverables varies.

Lack of well-defined process coordination.

Lack of commitment / motivation by clients.

Lack of project managers trained to work in a

collaborative working environment.

\section{Assisting Integration}

Pre-defined project requirements.

Commitment to innovation.

Early engagement of stakeholders.

Project start-up workshops.

Selecting team members based on abilities.

Willingness of team members.

Suitable contractual agreements.

Well distributed work load amongst members.

Detailed Bid and specifications helps in Public-Private

Partnership (PPP) projects.

Common goal for project stakeholders.

Back to front approach in construction process is beneficial for successful integration.

It is also important to consider how including this subject in education can benefit industry. This discussion with the focus group is summarized in Table 2.

Table 2: Benefits of including interdisciplinary collaboration in education.

\section{Benefits to Industry}

Incorporate work practices and procedures.

Industry makes graduates aware of current practices.

Students are taught applied knowledge.

Prepare students vocationally for industry.

Relevance to industry and project context is realistic.

Practicality of subject material.

Teaching flexibility to select professions is important.

Understanding differences in important.

Students are aware of roles and responsibilities.

Graduates are aware of project stages deadlines and times.

Students have procedural information about all disciplines.

\section{Benefits to Students}

Students get applied experience by learning on a live project.

Companies do not offer cadetships or internships and thus project-based learning helps them to achieve practical knowledge.

Enhances standards of detailed knowledge in students' background.

Insight into the particularities of their own profession is provided.

Students understand differences and develop abilities to address problem from different perspectives.

Stage 4: Reflective Observation. Think critically and analyze objectively. SFS and personal reflections are part of reflective observation. The questions in the survey can be classified into categories which are:

i) Subject matter content and delivery;

ii) Flipped Learning;

iii) Blended learning.

Table 3 represents a classification of the responses collected in SFS.

Table 3. Student Feedback Survey

\begin{tabular}{|r|l|}
\hline Classification & Meaning \\
\hline SD & Strongly Disagree \\
D & Disagree \\
N & Neutral \\
A & Agree \\
\hline SA & Strongly Agree \\
\hline
\end{tabular}

Figure 3 represents generalized student feedback on the subject based on satisfaction with the educational experience and subject deliverables. It is clear that the way the subject was delivered was not entirely positively received by the students. Based on these results, it is necessary to investigate what features adopted in delivering this subject were most disliked by students.

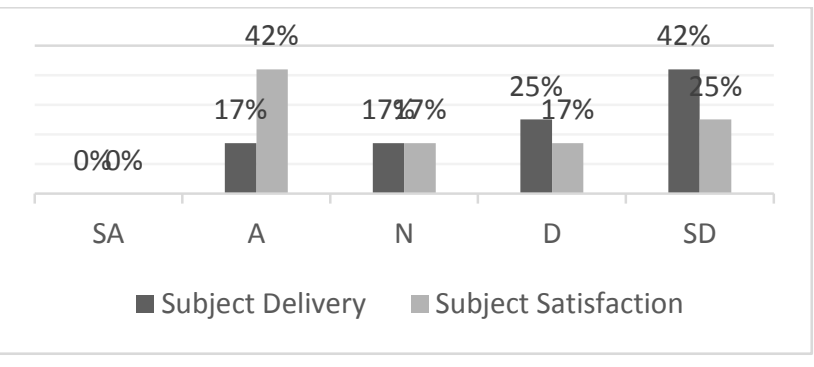

Figure 3: Survey results on subject satisfaction

Further analysis of the data collected via SFS surprisingly reveals that students were satisfied with the overall learning experience of this subject. There was however disagreement about way the subject was delivered.

Learning experiences in this subject were interesting and though provoking

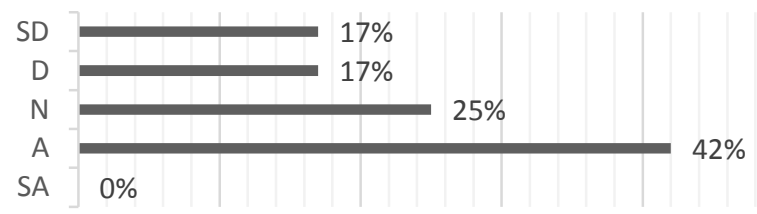

Figure 4: Survey results on students learning experience 
Data previously collected has demonstrated that project based learning and working in interdisciplinary teams are well accepted and appreciated concepts amongst students. Therefore, further investigation was done to differentiate between flipped and blended learning. From Figure 5, it is evident that the blended learning environment was not a problem in terms of subject resources and student experience.

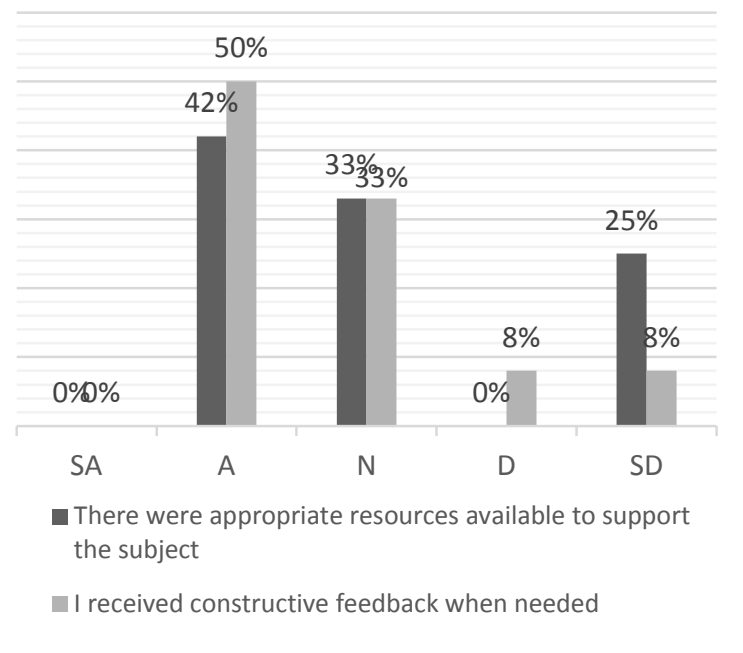

Figure 5: Survey results (in percentage) on subject resources.

Further analysis of the SFS data led to the conclusion that the flipped learning process was not popular amongst students in this subject. Figure 6 represents SFS results for flipped learning implementation in the subject's studio/tutorial sessions. There was strong disagreement regarding the way subject matter was delivered during tutorials. Students thought that it did not assist in understanding the subject requirements. The results demonstrate general subject satisfaction but demand an enhanced subject delivery process.

While the students appreciated the web-based learning approach and were happy with the subject resources it is obvious that the flipped learning process adopted needs reconsideration before the subject is offered again.

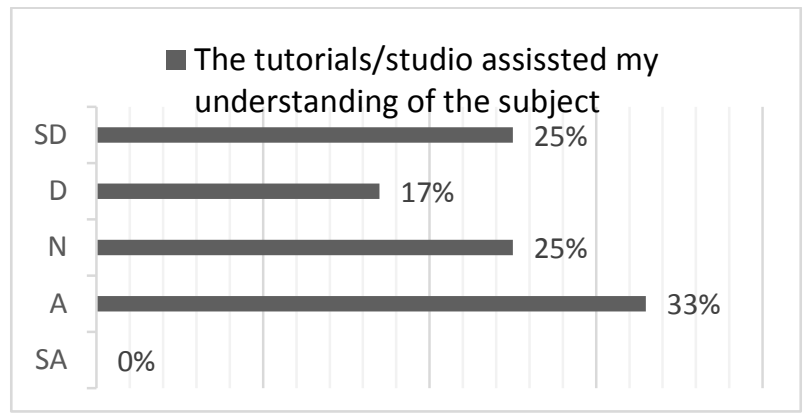

Figure 6: Survey results on flipped learning practices in subject tutorials.

As a part of the reflective cycle it was also necessary to record reflective inputs from industry professionals. Table 3 summarizes industry focus group suggestions and recommendations on such subjects in postgraduate university courses.

Table 3: Industry reflection on subject

\begin{tabular}{l} 
Industry recommendations \\
\hline Project selected should be achievable with an \\
interesting project brief. \\
New project with complex design and aesthetic value \\
and an attractive project. \\
Select a public space and define a hypothetical project \\
which is similar to urban planning project. \\
Realistic project and follow up the project \\
management process with the implementation of some \\
integration issues. \\
Small project to run from beginning through to \\
handover of completed building. \\
A problem which is applicable to all disciplines. \\
Structuring integrated studies in already existing \\
subjects. \\
Subject content can be part of communication, \\
leadership, lean construction, professional practice \\
subjects. \\
There should be no specific course on BIM but \\
students should be taught BIM nevertheless. \\
Companies should offer cadetships or internships. \\
Students to be taught applied knowledge. \\
Traditional architecture subjects have integration \\
topics and subjects which should be continued. \\
Practicality of subject material is important. \\
Teaching flexibility to select profession is important. \\
Selective enrollment process for students. \\
Reflective process for roles played. \\
Project based learning and minimum theoretical \\
teaching \\
Include staff from all disciplines content delivery. \\
\hline
\end{tabular}




\section{Conclusions}

While the idea of teaching multi-disciplinary teams using a live project is generally favoured by both the industry and students, improvements are required in several aspects of how the subject is taught. These being:

1. The project selected should be slightly more complex to provide a variety of challenges that require teamwork.

2. The brief should be expanded beyond the actual project to enable students to apply their various skills.

3. The university administrative set up (or enrolment process) needs to be modified to facilitate the right blend of students in the class.

4. Some more lectures need to be included during the workshops for download of technical information.

5. Flipped learning requires students to complete more preparatory activities prior to attending the workshops.

6. Helping students to learn soft skills to engage well in multi-disciplinary teams is more important than teaching them the use of technology.

One of the major benefits and innovations of this subject is that students understand the significance of process design and protocols for working in multidisciplinary teams.

\section{Acknowledgements}

This research project was funded by Learning and Teaching Grant awarded to the research team by the University of Technology Sydney.

\section{References}

[1] Tapscott, D. and A.D. Williams, Wikinomics: How mass collaboration changes everything. 2008: Penguin. com.

[2] Orr, K., Prototyping as a Paradigm for Linking Teaching and Research in the Architectural Design Studio, in Concrete Tectonics II, K. Orr, N. Nicholas, and J. Tringali, Editors. 2012, UTSePress / Blurb: Sydney. p. 20-26.

[3] AEC. AEC UK BIM Standard - A practical and pragmatic BIM standard for the Architectural, Engineering and Construction industry in the UK. . 2009 [cited 2012 5th Feb].

[4] Becerik-Gerber, B. and K. Kensek, Building
Information Modeling in Architecture, Engineering, and Construction: Emerging Research Directions and Trends. Journal of Professional Issues in Engineering Education and Practice, 2010. 136: p. 139.

[5] Fruchter, R., A/E/C teamwork: A collaborative design and learning space. Journal of Computing in Civil Engineering, 1999. 13(4): p. 261-269.

[6] Simoff, S.J. and M.L. Maher. Design education via web-based virtual environments. in Computing in Civil Engineering, Proceedings of the Fourth Congress of Computing in Civil Engineering, ASCE, NY. 1997.

[7] Fenves, S., Successes and further challenges in computer-aided structural engineering. Computing in Civil and Building Engineering, AA Balkema Publishers, 1995.

[8] Vanegas, J.A. and M. Guzdial. A collaborative and multimedia interactive learning environment for engineering education in sustainable development and technology. in Computing in Civil Engineering (1995). 1995. ASCE

[9] Osguthorpe, R. and C. Graham, Blended Learning Environments: Definitions and Directions. The Quarterly Review of Distance Education, 2003. 4( 3): p. 227-233

[10] Jonassen, D.H., Handbook of Research for Educational Communications and Technology. A Project of the Association for Educational Communications and Technology (AECT). 1996: ERIC.

[11] Marton, F. and A. Tsui, 2004. Classroom discourse and the space of learning.

[12] Oliver, M. and K. Trigwell, Can'Blended Learning'Be Redeemed? E-learning and Digital Media, 2005. 2(1): p. 17-26.

[13] Reason, P. and H. Bradbury, Handbook of action research: Participative inquiry and practice. 2001: Sage.

[14] Graham, C., Transforming spaces and identities: the contributions of professional staff to learning spaces in higher education. Journal of Higher Education Policy and Management, 2012. 34(4): p. 437-452.

[15] McKenzie, J., L. Pelliccione, and N. Parker, Developing peer review of teaching in blended learning environments: Frameworks and challenges. Hello! Where are you in the landscape of educational technology? Proceedings ascilite Melbourne 2008, 2008. 